\title{
HUBUNGAN PERAN BIMBINGAN AKADEMIK, KECERDASAN INTELEKTUAL, DAN MINAT DENGAN PRESTASI BELAJAR
}

\author{
Siti Patimah
}

\author{
Dosen Jurusan Kebidanan Poltekkes Kemenkes Tasikmalaya.
}

\begin{abstract}
ABSTRAK
Mahasiswa dalam perkuliahan selalu menemukan masalah baik akademik ataupun non akademik, sehingga diperlukan bimbingan dosen agar dapat menyelesaikan studinya dengan baik. Kesuksesan akademik dapat dilihat dari indek prestasi, tapi pencapaiannya dipengaruhi faktor internal (minat, intelegensi) dan ekternal (faktor lingkungan). Penelitian ini bertujuan mengetahui hubungan peran dosen pembimbing akademik, tingkat kecerdasan intelektual dan minat mahasiswa dengan prestasi belajar. Metoda penelitian analitik korelasi dengan pendekatan potong lintang. Sampel diambil dengan teknik simple random sampling, dengan subjek penelitian adalah 100 orang mahasiswa. Penelitian dilaksanakan di Program Studi D III dan D IV Kebidanan Tasikmalaya pada bulan Desember 2014 - Februari 2015. Uji statistik menggunakan Rank Spearman untuk melihat korelasi antar variabel. Hasil penelitian ditemukan peran pembimbing akademik kurang (44\%), tingkat kecerdasan intelektual $(47 \%)$ dan minat tinggi (82\%). Hasil analisis bivariabel ditemukan terdapat hubungan antara tingkat kecerdasan dengan prestasi $(p 0,005)$ dengan keeratan korelasi rendah ( $r s 0,278)$, terdapat hubungan antara minat dengan prestasi mahasiswa $(p 0,018)$ dengan keeratan korelasi rendah (rs -.237), dan tidak terdapat hubungan antara peran pembimbing akademik dengan prestasi mahasiswa $(p 0,142)$ dengan keeratan korelasi sangat rendah ( $r$ 0,148$)$. Kesimpulan penelitian bahwa tingkat kecerdasan intelektual dan minat berhubungan dengan prestasi belajar mahasiswa, sedangkan peran pembimbing akademik tidak berhubungan dengan prestasi belajar mahasiswa.

Kata kunci : Peran, Pembimbing akademik, tingkat kecerdasan, minat, prestasi.
\end{abstract}

\section{ABSTRAC}

Students in the lecture always found problems both academic and non-academic, so that the necessary guidance in order to finish his studies lecturer well. The success can be seen from the index of academic achievement, but the achievement was influenced internal factors including interest, intelligence and external (environmental factors). This study aims to determine the relationship of the role of supervisor of academic, intellectual level and interests of students with learning achievement. Analytical research method with cross sectional correlation. Samples were taken by simple random sampling technique, the research subjects were 100 students. Studies conducted in the D III and D IV Midwifery Tasikmalaya in December 2014 - February 2015. The statistical test using Spearman Rank to see the correlation between variables. Results of research on the role of counselors found less (44\%) level of intelligence (47\%) and high interest (82\%). Results bivariable analysis found there is a relationship between the intelligence level of achievement (p0.005) with the closeness of the low correlation (rs 0.278), there is a relationship between the interest of the student achievement (p0.018) with the closeness of the low correlation (rs-.237), and there is no correlation between the role of academic counselors with student achievement $p$ 0.142) with the closeness of the correlation is very low (rs0.148). Conclusion of the study that the level of intellectual and interest related to student achievement, while the role of academic counselors do not relate to the achievement of students.

Keywords: role, academic supervisor, level of intelligence, interests, achievements. 


\section{PENDAHULUAN}

Secara umum masalah yang dihadapi mahasiswa meliputi masalah akademik dan non akademik. Masalah akademik yaitu hambatan atau kesulitan yang dihadapi mahasiswa dalam merencanakan, melaksanakan dan mengoptimalkan perkembangan belajarnya. Masalah non akademik merupakan kesulitan yang dihadapi mahasiswa dalam mengelola kehidupannya sendiri dan menyesuaikan diri dengan kehidupan sosial, baik di lingkungan kampus, tempat kerja maupun lingkungan tempat tinggal. Dalam upaya mengembangkan diri, menghindari serta mengatasi hambatan dan masalah yang dihadapi maka diperlukan bimbingan secara intensif dan sistematik dari para dosen/counselor.

Kesuksesan akademik mengacu pada keberhasilan mahasiswa dalam mengikuti perkuliahan sejak semester awal hingga diwisuda. Keberhasilan ini dapat dilihat dari indeks prestasi (IP). Pencapaian kesuksesan tersebut dipengaruhi oleh berbagai hal antara lain faktor internal dan eksternal. Faktor internal adalah yang terdapat pada diri seseorang termasuk kondisi fisiologis secara umum, kondisi panca indera, minat, intelegensi/kecerdasan, bakat, dan motivasi sedangkan faktor eksternal yang terdapat di luar diri seseorang meliputi faktor lingkungan (Slameto, 2003).

Perguruan tinggi memikul tanggung jawab dalam pembinaan mahasiswa untuk mencapai kesuksesan yakni dengan cara mendorong mahasiswa untuk melakukan kegiatan studi secara optimal, baik dalam perkuliahan dan kehidupan mahasiswa selama menjalani studi (Silitonga, 2008). Kondisi tersebut mengisyaratkan bahwa bantuan pelayanan kepada mahasiswa sangat diperlukan dengan cara mengefektifkan bimbingan akademik melalui

\section{METODE PENELITIAN}

Metoda penelitian ini adalah analitik korelasi dengan pendekatan potong lintang. dosen pembimbing akademik (Ginting, 2003).

Dosen Pembimbing Akademik turut menentukan prestasi belajar mahasiswa, dosen diharapkan mampu untuk memberikan layanan bantuan kepada mahasiswa bimbingannya dalam upaya keberhasilan studi. Melalui peranannya sebagai pembimbing, dosen diharapkan mampu mendorong mahasiswa untuk senantiasa belajar dalam berbagai kesempatan melalui berbagai sumber dan media. Dosen hendaknya mampu membantu setiap mahasiswa untuk secara efektif menggunakan berbagai kesempatan belajar dan berbagai sumber media belajar (Slameto, 2003).

Namun terkadang bimbingan akademik yang dijalankan belum sesuai dengan fungsi dan tujuannya. Hal ini mengakibatkan permasalahan akademik yang dihadapi mahasiswa dapat mengganggu proses penyelesaian studi pada akhirnya potensi yang dicapai tidak optimal (llyas,2008).

Berdasarkan uraian tersebut maka tujuan dari penelitian ini adalah untuk mengetahui hubungan peran dosen pembimbing akademik, tingkat kecerdasan intelektual dan minat mahasiswa dengan Prestasi belajar Mahasiswa di Prodi D III dan D IV Kebidanan Tasikmalaya. Adapun Manfaat penelitian diharapkan dapat menambah wawasan dosen tentang pentingnya peran pembimbingan akademik dalam proses perkuliahan mahasiswa di perguruan tinggi. Diharapkan mahasiswa dapat sukses dalam menjalani perkuliahan dan lulus tepat waktu. Manfaat lainnya Diharapkan dapat menjadi masukan untuk peningkatan peran dosen pembimbing akademik dan memperbaiki sistem input mahasiswa dalam seleksi penerimaan mahasiswa baru di Poltekkes Tasikmalaya.

Populasi pada penelitian ini adalah semua mahasiswa program D III dan D IV 
Kebidanan Tasikmalaya. Sampel diambil dengan teknik simple random sampling. Besar ukuran sampel sebagai subjek penelitian adalah 100 orang mahasiswa.

Penelitian diilaksanakan di Program Studi D III dan D IV Kebidanan Tasikmalaya pada bulan Desember 2014 - Februari
2015. Uji statistik menggunakan Rank Spearman untuk melihat korelasi antar variabel. Keeratan korelasi antara variabel bebas dan variabel terikat dilihat berdasarkan koeefisien korelasi yang berdasarkan kriteria Guillford.

\section{HASIL}

\section{Peran pembimbing akademik dengan Prestasi belajar mahasiswa}

Tabel 1. Tabel silang Peran pembimbing akademik dengan Prestasi belajar mahasiswa

\begin{tabular}{cccccc}
\hline \multirow{2}{*}{ Peran } & \multicolumn{2}{c}{ IPK } & & Total & $\begin{array}{c}\boldsymbol{\rho} \\
\text { Value }\end{array}$ \\
\cline { 2 - 3 } & B & A $n n n n n$ & & 0.142 \\
Kurang & 34 & 10 & & 44 & \\
Cukup & 28 & 8 & & 36 & \\
Baik & 11 & 9 & 20 & 100 \\
\hline Total & 73 & 27 & &
\end{tabular}

Ket : Berdasarkan Uji Rank spearman

\section{Tingkat kecerdasan intelektual dengan Prestasi belajar mahasiswa}

Tabel 2. Tabel silang Tingkat kecerdasan intelektual dengan Prestasi belajar mahasiswa

\begin{tabular}{cccccc}
\hline \multirow{2}{*}{$\mathbf{Q}$} & \multicolumn{2}{c}{ IPK } & & Total & P \\
\cline { 2 - 3 } & B & $\mathbf{A}$ & & Value \\
\hline Dull normal & 2 & 0 & & 0.005 \\
Average & 40 & 7 & & \\
Average + & 24 & 15 & 39 & \\
Bright normal & 7 & 5 & 12 & \\
\hline Total & 73 & 27 & 100 & \\
\hline
\end{tabular}

\section{Minat dengan Prestasi belajar mahasiswa}

Tabel 3. Tabel silang minat dengan Prestasi belajar mahasiswa

\begin{tabular}{|c|c|c|c|c|}
\hline \multirow{2}{*}{ Minat } & \multicolumn{2}{|c|}{ IPK } & \multirow{2}{*}{ Total } & \multirow{2}{*}{$\begin{array}{c}\rho \\
\text { Value }\end{array}$} \\
\hline & B & A & & \\
\hline Rendah & 3 & 2 & 5 & 0.018 \\
\hline Sedang & 6 & 7 & 13 & \\
\hline Tinggi & 64 & 18 & 82 & \\
\hline Total & 73 & 27 & 100 & \\
\hline
\end{tabular}

4. Hubungan peran pembimbing akademik, tingkat kecerdasan intelektual, dan minat mahasiswa dengan prestasi belajar mahasiswa

Tabel 4. Hubungan peran pembimbing akademik, tingkat kecerdasan intelektual, dan minat mahasiswa dengan prestasi belajar mahasiswa

\begin{tabular}{clcc}
\hline No. & \multicolumn{1}{c}{ Korelasi } & rs & Nilai $\boldsymbol{\rho}$ \\
\hline 1 & Skor peran dengan prestasi & 0.148 & 0.142 \\
2 & Skor Tingkat kecerdasan dengan prestasi & 0.278 & 0.005 \\
3 & Skor Minat dengan prestasi & -.237 & 0.018 \\
\hline
\end{tabular}




\section{PEMBAHASAN}

1. Hubungan Peran pembimbing akademik dengan prestasi belajar mahasiswa.

Variabel peran pembimbing akademik dalam penelitian ini adalah peran dilaksanakan oleh pembimbing akademik dalam proses bimbingan akademik. Hasil menunjukkan bahwa sebagian besar peran pembimbing akademik dalam kategori kurang.

Dosen PA (Pembimbing akademik) mempunyai peran untuk membantu dan membimbing mahasiswa untuk menyelesaikan tugasnya sebagai mahasiswa, pengembangkan pandangan, mengambil keputusan dan bertanggung jawab terhadap dirinya sendiri.

Dosen Pembimbing Akademik turut menentukan prestasi belajar mahasiswa, dosen diharapkan mampu untuk memberikan layanan bantuan kepada mahasiswa bimbingannya dalam upaya keberhasilan studi. Melalui peranannya sebagai pembimbing, dosen diharapkan mampu mendorong mahasiswa untuk senantiasa belajar dalam berbagai kesempatan melalui berbagai sumber dan media. Dosen hendaknya mampu membantu setiap mahasiswa untuk secara efektif menggunakan berbagai kesempatan belajar dan berbagai sumber media belajar (Slameto, 2003).

Untuk mengoptimalkan perannya Dosen sebagai pembimbing akademik harus memahami peraturan akademik agar dapat melaksanakan tugas dan tanggung jawabnya sebagai PA. Namun kenyataannya para mahasiswa belum memanfaatkan peran PA secara optimal. Pada umumnya mahasiswa menemui PA pada saat perwalian untuk menanda tangani KRS. Berdasarkan hasil penelitian maka peran PA harus terus menerus ditingkatkan kualitasnya.

Penelitian Chasanah (2012) menyebutkan bahwa persepsi mahasiswa tentang pembimbing akademik berhubungan secara signifikan dengan prestasi belajar. Pendapat lain juga menyebutkan bahwa bimbingan akademik ada hubungan yang bermakna dengan prestasi belajar (Sunarsih, 2010). Sejalan dengan dua pendapat sebelumnya penelitian Hapidudin (2008) menemukan bahwa pembimbingan akademik memiliki peran penting dalam meningkatkan hasil studi mahasiswa.

Hasil penelitian ini menunjukkan tidak ada hubungan yang signifikan antara peran dosen pembimbing akademik dengan prestasi mahasiswa. hal tersebut dimungkinkan berdasarkan data diperoleh tingkat kecerdasan mahasiswa sebagian besar dalam kategori average dan average+. Minat mahasiswa juga dalam kategori tinggi. Diperkirakan mahasiswa tidak mengalami kesulitan/permasalahan dalam belajar. Selain itu prestasi juga dipengaruhi oleh faktor ekternal yaitu lingkungan (orang tua, keluarga, temanteman dan masyarakat (Syah M, 2008, azwar 1999).

2. Hubungan Tingkat kecerdasan intelektual dengan prestasi belajar mahasiswa

$$
\text { Variabel tingkat kecerdasan }
$$
intelektual dalam penelitian ini tingkat kecerdasan mahasiswa berdasarkan hasil uji psikotest pada saat mahasiswa masuk. Hasil menunjukkan bahwa sebagian besar mahasiswa mempunyai tingkat kecerdasan average dan average+.

Kemampuan intelektual adalah kemampuan yang diperlukan untuk menjalankan kegiatan mental, berpikir, menalar dan memecahkan masalah (Robbins, 2001:57). Menurut Purwanto (2004) bahwa ada beberapa faktor yang dapat mempengaruhi intelegensi yang mengakibatkan terjadinya perbedaan antara intelegensi seseorang dengan yang lain. Adapun faktor yang dapat mempengaruhi tingkat intelegensi seseorang, di antaranya pembawaan, kematangan, pembentukan, minat dan kebebasan.

Dengan tingkat kecerdasan yang tinggi seseorang akan lebih mudah untuk mengikuti dan memahami materi pembelajaran, berbeda dengan orang dengan tingkat kecerdasan kurang. Menurut Robbins (2001) dalam kecerdasan 
intelektual terdapat tujuh dimensi yaitu kecerdasan angka, pemahaman verbal, kecepatan persepsi, penalaran induktif, penalaran deduktif, visualisasi parsial dan daya ingat.

Hasil penelitian ini sesuai dengan hasil penelitian Gunadi dkk (2012) yang menunjukkan bahwa intelegensi berhubungan positif dan signifikan terhadap prestasi akademik. Demikian juga hasil penelitian di SMA N 99 Jakarta menemukan bahwa tingkat intelegensi berpengaruh terhadap prestasi akademik secara signifikan ( Arini kadek, 2008).

Menurut Syah M (2008) menyebutkan faktor - faktor yang mempengaruhi preatasi belajar yaitu faktor internal, faktor eksternal dan faktor pendekatan belajar. Faktor internal meliputi faktor fisiologis dan psikologis (intelegensi, sikap, minat, bakat dan motivasi). Faktor eksternal yaitu faktor lingkungan sosial dan nonsosial.

3. Hubungan minat dengan prestasi belajar mahasiswa

Variabel minat dalam penelitian in adalah minat mahasiswa untuk kuliah di jurusan kebidanan dan menjadi bidan. Hasil menunjukkan bahwa sebagian besar mahasiswa mempunyai tingkat minat yang tinggi.

Menurut Slamento (2010) menyatakan bahwa minat adalah suatu rasa lebih suka dan rasa ketertarikan pada suatu hal dan aktivitas, tanpa ada yang menyuruh. Minat dapat menjadi sebab terjadinya suatu

\section{KESIMPULAN}

Simpulan yang dapat diambil
berdasarkan hasil penelitian dan pembahasan mengenai hubungan peran pembimbing akademik, tingkat kecerdasan intelektual dan minat mahasiswa dengan prestasi belajar mahasiswa, adalah sebagai berikut :

1. Tidak terdapat hubungan antara peran pembimbing akademik dengan prestasi belajar mahasiswa.

2. Terdapat hubungan antara tingkat kecerdasan intelektual dengan prestasi belajar mahasiswa. kegiatan dan hasil yang akan diperoleh. Apabila seseorang menaruh perhatian pada sesuatu, maka minat akan menjadi motif yang kuat untuk berhubungan secara aktif dengan sesuatu yang menarik minatnya (Hurlock, 1999).

Dengan minat yang tinggi seorang mahasiswa akan belajar dengan tujuan yang jelas.Dan Minat akan semakin besar apabila seseorang merasakan bermanfaat atau tidaknya sesuatu yang dipelajari bagi individu. Apabila mata kuliah kurang dirasakan bermanfaat bagi perkembangan dirinya, orang cenderung untuk menghindar.

Menurut Syah M (2008) dan Azwar (1999) faktor yang mempengaruhi prestasi belajar yaitu faktor internal (faktor fisiologis dan psikologis ). Faktor psikologis seperti intelegensi, sikap, minat, bakat dan motivasi.

Faktor eksternal dibagi menjadi 2 macam yaitu faktor lingkungan sosial dan lingkungan non sosial. Lingkungan sosial meliputi lingkungan orang tua, keluarga, sekolah dan masyarakat. lingkungan sosial sekolah meliputi guru/dosen, staf administrasi dan teman-teman sekolah.

Hasil penelitian ini sesuai dengan penelitian yang dilakukan oleh Prasetyo (2012) menemukan bahwa minat berpengaruh terhadap prestasi belajar. Berdasarkan penjelasan tersebut maka diperoleh kesimpulan bahwa minat berhubungan dengan prestasi belajar mahasiswa.

3. Terdapat hubungan antara minat mahasiswa dengan prestasi belajar mahasiswa.

4. Berdasarkan hasil penelitian yang telah diuraikan diatas, maka dapat dikemukakan saran sebagai berikut :

a. Peran pembimbing akademik ada dalam kategori kurang. Berdasarkan hal tersebut maka dalam memberikan bimbingan akademik harus lebih ditingkatkan kualitas dan kuantitasnya sehingga input mahasiswa yang 
sudah baik bisa ditingkatkan lagi potensinya.

b. Perlunya dibuat program bimbingan akademik, sehingga pembimbing akademik tidak hanya menyelesaikan

\section{REFERENSI}

Arini S, 2008. Pengaruh tingkat intelegensi dan motivasi belajar terhadap prestasi akademik siswa kelas II SMA Negeri 99 Jakarta. Jakarta.

Azwar, 1999. Dasar-dasar psikometri. Pustaka pelajar.Yogyakarta.

Chasanah, 2012. Hubungan persepsi mahasiswa tentang pembimbing akademik dan motivasi belajar dengan prestasi belajar di Program Studi S1 Kesehatan masyarakat STIKES Wira Husada. Tesis. Universitas sebelas maret. Yogyakarta

Ginting C, 2003. Kiat belajar di Perguruan Tinggi. Grasindo. Jakarta.

Gunadi L, 2012. Hubungan antara intelegensi dan motivasi berprestasi terhadap prestasi akademik. STP. Jakarta.

Hapidudin, Hasyim, 2011, Peran pembimbing akademik dalam mengoptimalkan hasil studi mahasiswa; Studi pada politeknik Negeri Jakarta, Jakarta.

Hurlock, 1999. Perkembangan anak. Erlangga. Jakarta. masalah yang ditemui tetapi juga menyiapkan mahasiswa untuk mampu menyelesaikan studinya tepat waktu dan mampu siap bersaing di tempat kerja.

Prasetyo H, 2012. Pengaruh tingkat kepuasan mahasiswa dan minat belajar terhadap prestasi belajar praktek dan teori pada mata diklat body and painting di SMK PIRI 1 Yogyakarta tahun 2011/2012. Yogyakarta.

Robbins, 2001. Organizational Behavior, 9thEd. Upper Saddle River New Jersey 07458 : Prentice Hall International.

Slamento, 2003. Belajar dan Faktor - Faktor yang mempengaruhinya. Rineka Cipta. Jakarta.

Syah M, 2008. Psikologi belajar. Raja Grafindo persada, Jakarta

Slamento, 2010. Belajar dan faktor - faktor yang mempengaruhinya. Rineka Cipta,Jakarta.

Sunarsih T, 2009. Hubungan antara motivasi belajar, kemandirian belajar dan bimbingan akademik terhadap prestasi belajar mahasiswa di Stikes A. Yani Yogjakarta, Tesis, Universitas sebelas maret, Surakarta. diakses dari eprints.uns.ac.id/2537/1/ 134420808201008111.pdf 